5. Crawhall, J. C., Mamer, O., Tjoa, S., and Claveau, J. C.: Urinary phenolic acids in tyrosinemia. Identification and quantitation by gas chromatography-mass spectrometry. Clin. Chim. Acta, 34: 47 (1971).

6. Curtius, H.-Ch, Vollmin, J. A., and Baerlocher, K.: The use of deuterated phenylalanine for the elucidation of the phenylalanine-ty rosine metabolism. Clin. Chim. Acta, 37: 277 (1972).

7. Fieser, L. F., and Fieser, M.: Reagents for Organic Synthesis, p. 191 (John Wiley \& Sons, Inc., 1967).

8. Gentz, J., Lindblad, B., Lindsteds, S., and Zetterstrom, R.: Studies on the metabolism of the gas-liquid chromatographic method. J. Lab. Clin. Med., 74: 185 (1969).

9. Glick, H., and Allen, A. C.: Diet-induced metabolic acidosis in prematurely born infants, J. Pediat., 78: 1061 (1971).

10. Horning, E. C., and Horning, M. G.: Human metabolic profiles obtained by GC and GC/MS. J. Chromatogr. Sci., 9: 129 (1971).

11. Horning, E. C., and Horning, M. G.: Metabolic profiles: gas-phase methods for analysis of metabolites. Clin. Chem., 17: 802 (1971).

12. Jellum, E., Stokke, O., and Eldjarn, L.: Screening for metabolic disorders using gas-liquid chromatography mass spectrometry and computer technique. Scand. J. Clin. Lab. Invest., 27: 273 (1971).

13. Kildeberg, P.: Clinical acid base physiology. In: Studies in Neonates, Infants and Young Children (Munksgaard, Copenhagen, 1968).

14. Kildeberg, P.: Disturbances of hydrogenion homeostasis. II. Late metabolic acidosis. Acta Paediat. Scand., 53: 517 (1964).

15. Kretchmer, N.: Enzymatic patterns during development. Pediatrics, 23: 606 (1959).

16. Kretchmer, N., Levine, S. Z., and McNamara, H.: Certain aspects of tyrosine metabolism in the young. (I). The development of the tyrosine oxidising system in human liver. J. Clin. Invest., 2: 236 (1965).

17. La Du, B. N., and Gjessing, L. R.: Tyrosinosis and Tyrosinemia in The Metabolic Basis of Inherited Disease, Ed. 3, Chap. 12 (McGraw-Hill Book Co., 1972).

18. Levine, S. Z., Dann, M., and Marples, E.: A defect in tyrosine and phenylalanine metabolism in premature infants. (III). Demonstration of the irreversible conversion of phenylalanine to tyrosine in the human organism. J. Clin. Invest., 22: 551 (1943).

19. Levine, S. Z., Gordon, H. H., and Marples, E.: A defect in tyrosine and phenylalanine metabolism in premature infants. (ii). Spontaneous occurrence and eradication by vitamin C. J. Clin. Invest., 20: 209 (1941).

Copyright $(1975$ International Pediatric Research Foundation, Inc.
20. Levine, S. Z., Marples, E., and Gordon, H. H.: A defect in tyrosine and phenylalanine metabolism in premature infants. (I). Identification and assay of intermediary products. J. Clin. Invest., 20: 199 (1941).

21. Menkes, J. H., Chernick, V., and Ringel, B.: Effect of elevated tyrosine on subsequent intellectual development of premature infants. J. Pediat., 69: 583 (1966).

22. Menkes, J. H., Welcher, D. W., Levi, H. S., Dallas, J., and Gretsky, N. E.: Relationship of elevated blood tyrosine to the ultimate intellectual performance of premature infants. Pediatrics, 49: 218 (1972).

23. Partlington, M. W., Delahaye, D. J., Masotti, R. E., Read, J. H., and Roberts, B.: Neonatal tyrosinemia: A follow-up study. Arch. Dis. Childhood, 43: 195 (1968).

24. Ranlov, P., and Siggaard-Anderson, O.: Late metabolic acidosis in premature infants. Acta Paediat. Scand., 54: 531 (1965).

25. Reynolds, W. E., Bacon, V. A., Bridges, J. C., Coburn, T. C., Halpern, B., Lederberg, J., Levinthal, E. C., Steed, E., and Tucher, R. B.: A computer operated mass spectrometer system. Anal. Chem., 42: 1122 (1970).

26. Schain, R. J., and O'Brien, K.: Longitudinal studies of acid-base status in infants with low birth weight. J. Pediat., 70: 885 (1967).

27. Svenningsen, N. W.: Metabolic acidosis in preterm infants during the first weeks of life. Acta Paediat. Scand., 56: 439 (1967).

28. Svenningsen, N. W., and Lindquist, B.: Incidence of metabolic acidosis in term, preterm and small-for-gestational age infants in relation to dietary protein intake. Acta Paediat. Scand., 62: 1 (1973).

29. Wadman, S. K., Van Sprang, F. J., Mass, J. W., and Ketting, D.: An exceptional case of tyrosinosis. J. Ment. Defic. Res., 12: 269 (1968).

30. This work was supported by a grant from the Manned Space Center, NASA (Grant no. NGR 05-020-632) and RR-00612, from the National Institutes of Health, Grant no. RR-81 from the General Clinical Research Centers Program of the Divisions of Research Resources, National Institutes of Health, Research Grant no. HD-02147, and Training Grant no. HD-00049 from the National Institutes of Health.

31. Requests for reprints should be addressed to: A. Duffield, Ph.D., Department of Genetics, Stanford University Medical Center, 300 Pasteur Dr., Stanford, Calif. 94305 (USA).

32. Accepted for publication December 3, 1974.

\title{
Sex Differential of Survival during Perinatal Period: An Immunologic Phenomenon?
}

\author{
MICHEL C. VERNIER(36) \\ Division of Epidemiology, School of Public Health, University of California, Berkeley, California, USA
}

Extract

The sex-differential early neonatal mortality experienced by a population of 27,243 neonates has been analyzed in relation to sex-related reproductive antecedents of their mothers. An association between the risk of dying of a neonate and the sex of previous pregnancies of its mother has been found: the risk decreases with a previous pregnancy of the same sex as the neonate, and increases with one of the opposite sex. Repeated pregnancies of same sex increase the phenomenon. An immunologic hypothesis has been formulated from these results: sex-differential survival of conceptuses during the perinatal period would be due to sex-differential conceptomaternal immunologic interactions. An advantage in survival of the female fetus results from these interactions in primiparous mothers. However, immunologic behavior of the mother is 
altered by previous contact with fetal antigens. Consequently sex-differential survival varies with sex-related antecedents of the gravida. Previous sensitization of the gravida by male pregnancy provides an advantage in survival for a subsequent male conceptus, and previous sensitization by female pregnancy provides an advantage in survival for a subsequent female conceptus.

\section{Speculation}

A confirmation of an association between mortality during the overall perinatal period and sex-related reproductive antecedents of the mother could support an immunologic explanation of sex-differential survival. This would provide a new approach for analyzing sex-differential biologic phenomena.

The probability of surviving through the perinatal period is higher for a female than for a male neonate. No definite explanation of this phenomenon has been given yet. The development of knowledge in the field of immunology of reproduction indicates that immunologic relationships between gravida and conceptus play a very important role in the survival of the latter. Because of its paternally inherited antigens, the fetus is an allograft for its mother. The fetus can induce immunity and react to sensitization (5). The mother is able to respond to fetal antigenic stimulation by producing humoral $(17,18)$ and cellular antibodies (29). There is also evidence of passage across the placenta of elements from both fetal $(4,11,13,21,25,34)$ and maternal origin $(22,31)$. However, by a mechanism not completely elucidated, immunologic rejection usually does not take place. On the contrary, it seems that antigenic dissimilarity between conceptus and gravida could be an advantage. This seems to favor the implantation of the blastocyst in mice (6). Nevertheless, under certain circumstances, immunologic interactions are harmful for the fetus. Hemoisoimmune disease because of Rhesus factor or to antigens of ABO blood groups is the best documented example of this type of perinatal pathology.

Whatever the consequences of the immunologic interactions on the survival of the fetus, they are expected to vary with the differences in fetal antigenicity. There has been speculation about sex-differential antigenicity. In mice, there is a male specific antigen capable of inducing graft rejection under certain experimental conditions (10). In the human, two opposite hypotheses concerning sex-related antigenicity of the conceptus were formulated in order to explain the sex ratio at birth biased in favor of the male. For some authors, the male blastocyst differs more antigenically from its mother than does the female blastocyst. Consequently it would be preferentially implanted (20). For others, maternofetal incompatibility due to $\mathrm{Xg}^{\mathrm{a}}$ blood group antigens, which can happen only with female conceptuses, could be responsible for an excess of female wastage in early gestation period $(7,26)$. A recent study of variation of placental size in neonates, with the reproductive history of the mother, supports a hypothesis of sex-differential immunologic conceptomaternal interactions during normal pregnancy (32). The purpose of the present study is to explore the relevance of an immunologic hypothesis for the sex-differential of perinatal survival. According to this hypothesis, sex-differential survival would be due to sex-differential conceptomaternal interactions.

Repeated contacts with a foreign fetal antigen seem able to induce changes in the immunologic status of the gravida. Thus, multiparity in a mouse mated with a male of an unrelated strain induces a tolerance to paternal grafts (3). On the contrary, cell-mediated immunity against paternal transplantation antigens has been shown to be increased in mice with successive interstrain pregnancies (24). Sensitization of the mother to erythrocyte and leukocyte antigens increases with parity $(12,13)$. The increase of placental weight and birth weight with parity has been interpreted as a result of sensitization of the mother to paternal antigens (33). It is thus conceivable that fetal antigen can induce tolerance or sensitization of the gravida and alter her immunologic behavior in the course of a subsequent pregnancy. On such an assumption is based the exploration of the immunologic hypothesis of sex-differential survival by means of analysis of perinatal mortality, in relation to sex-related reproductive history of the gravida.

The perinatal period extends, according to the WHO definition, from the $28 \mathrm{th}$ week of gestation to the 7 th day of life. There are two important limitations in studying the late fetal mortality by means of statistical collections; one concerning sex-identification of the dead fetus, the other concerning size estimation of populations at risk. There is no such difficulty in studying early neonatal mortality (1st week). The mortality experienced by a population of neonates has been analyzed in order to determine whether a relation exists between a neonate's risk of dying during the first days of its life and the sex of the previous pregnancies of its mother.

\section{EXPERIMENTAL PROCEDURE}

\section{MATERIALS}

The basic information is derived from the Child Development Study (CDS). This continuing study, begun in 1959, is conducted on members of the Kaiser Foundation Health Plan (a prepaid medical program), who reside in the San FranciscoEast Bay area. All women of the plan who report for prenatal care in certain of the Kaiser clinics in Northern California constitute the study population. The study population represents a broad range in economic, social, and educational characteristics, and is not atypical of an employed population. The aim of the CDS is to collect, by means of interviews, medical records, blood and placental examinations, information pertinent to the study of the subsequent development of the child. An interview is obtained generally early in pregnancy and concerns particularly the reproductive history of the gravida.

From the CDS data a population of neonates has been constituted. They represent the live births of all the pregnancies reported in the interview on the reproductive history of the gravida. Excluded from the study were $13.7 \%$ of male and $13.4 \%$ of female neonates because of a lack of information concerning the sex of previous pregnancies of their mothers. The study population includes 13,962 male and 13,281 female neonates.

\section{METHODS}

The population study has been divided into six cohorts. The neonates of a given cohort were born from mothers having the same reproductive history: cohort $I$, neonates of parity 1 mothers; cohort II, neonates of parity 2 mothers (the conceptus of the first pregnancy was male); cohort III, neonates of parity 2 mothers (the conceptus of the first pregnancy was female); cohort $I V$, neonates of mothers of parity greater than 2 (the two immediately preceding pregnancies were male); cohort $V$, neonates of mothers of parity greater than 2 (of the two immediately preceding pregnancies, one was male, the other female); cohort VI, neonates of mothers of parity greater than 2 (the two immediately preceding pregnancies were female).

Parity was defined in this study as the number of known pregnancies regardless of the outcome. Mortality rates during the neonatal period were computed for male and for female neonates of each cohort. The sex-differential mortality was measured by the relative risk of dying of a male neonate compared with a female neonate. The relative risk is the ratio of male mortality rate to female mortality rate (23). 


\section{RESULTS}

The overall rate of early neonatal mortality (Table 1) was $17.0 / 1,000$ live births. The variations of mortality among the cohorts were small. At parity 2 (cohorts $I I$ and $I I I$ ), mortality was slightly higher than at other parities. The classic U-shaped association between neonatal mortality and parity was not found (1). This could be caused by the decline of mortality throughout the extended period during which the births of participating babies took place.

The male rate of early neonatal mortality (Table 2) was $19.8 / 1,000$ live births; at parity $1,19.9 / 1,000$; at parity 2 , $20.7 / 1,000$; at parity greater than $2,19.1 / 1,000$. Male mortality at parity 2 was higher (22.4) if the first pregnancy of the mother had been female than if it had been male (19.2). The difference is not statistically significant. Male mortality at parity greater than 2 was the lowest $(10.8)$ if the two last pregnancies had been male and higher if they had been unlike (21.9) or female (23.1). The differences between cohort IV and cohorts $V$ and $V I$ are statistically significant $(P<0.05)$.

The female rate of early neonatal mortality (Table 3 ) was $13.9 / 1,000$ live births; at parity $1,13.8 / 1,000$, at parity 2 , $14.9 / 1,000$, at parity greater than $2,13.2 / 1,000$. Female mortality at parity 2 was lower (11.9) if the first pregnancy of the mother had been female than if it had been male (17.9). However, the difference is not statistically significant. Female mortality at parity greater than 2 was the highest $(22.1)$ if the two last pregnancies had been male and lower if they had been unlike (10.8) or female (8.6). The differences between cohort $I V$ and cohorts $V$ and $V I$ are statistically significant $(P<$ 0.05 ).

The risk of dying (Table 4) of a male neonate during the first week of his life was $42 \%$ higher than that of a female neonate. The relative risk (r.r.) varied very little with the parity; parity 1, 1.44; parity 2, 1.38; parity greater than 2, 1.44. At parity 2 , the risk of dying of a male neonate or of a female neonate was about the same if the first pregnancy of the mother had been male (r.r., 1.07). The risk of dying of a male neonate was about 2 times the risk of dying of a female neonate if the first pregnancy had been female (r.r., 1.92). At parity greater than 2 , the risk of dying of a male neonate was half of that of a female neonate (r.r., 0.45) if the two last pregnancies had been male. It was more than the double in the other cases: r.r. was 2.03 if the two last pregnancies had been unlike, and r.r. was 2.69 if the two last pregnancies had been female.

\section{DISCUSSION}

The risk of dying of a neonate during the first days after birth is thought to be higher for males than for females. The present study suggests that this phenomenon is not constant

Table 1. Neonatal mortality of neonate according to reproductive history of mother

\begin{tabular}{|c|c|c|c|c|c|}
\hline \multirow[b]{2}{*}{ Cohort } & \multicolumn{2}{|c|}{ Reproductive history of mother } & \multicolumn{3}{|c|}{ Neonatal mortality } \\
\hline & Parity & $\begin{array}{l}\text { Sex of previous } \\
\text { pregnancies }\end{array}$ & $\begin{array}{l}\text { Popula- } \\
\text { tion }\end{array}$ & Deaths & Rate \\
\hline$I$ & 1 & None & 11,167 & 189 & 16.9 \\
\hline$I I$ & 2 & Male & 3,985 & 74 & 18.6 \\
\hline III & 2 & Female & 3,587 & 61 & 17.0 \\
\hline IV & $>2$ & Male and male & 2,296 & 37 & 16.1 \\
\hline$V$ & $>2$ & Male and female ${ }^{1}$ & 4,192 & 68 & 16.2 \\
\hline$V I$ & $>2$ & Female and female ${ }^{1}$ & 2,016 & 33 & 16.4 \\
\hline Total & & & 27,243 & 462 & 17.0 \\
\hline
\end{tabular}

${ }^{1}$ Sex of the last two previous pregnancies.
Table 2. Neonatal mortality of male neonate according to reproductive history of mother

\begin{tabular}{|c|c|c|c|c|c|}
\hline \multirow[b]{2}{*}{ Cohort } & \multicolumn{2}{|c|}{ Reproductive history of mother } & \multicolumn{3}{|c|}{ Neonatal mortality } \\
\hline & Parity & $\begin{array}{c}\text { Sex of previous } \\
\text { pregnancies }\end{array}$ & $\begin{array}{l}\text { Popula- } \\
\text { tion }\end{array}$ & Deaths & Rate \\
\hline$I$ & 1 & None & 5,792 & 115 & 19.9 \\
\hline II & 2 & Male & 2,033 & 39 & 19.2 \\
\hline$I I I$ & 2 & Female & 1,788 & 40 & 22.4 \\
\hline$I V$ & $>2$ & Male and male ${ }^{1}$ & 1,208 & 13 & 10.8 \\
\hline$V$ & $>2$ & Male and female ${ }^{1}$ & 2,057 & 45 & 21.9 \\
\hline$V I$ & $>2$ & Female and female ${ }^{1}$ & 1,084 & 25 & 23.1 \\
\hline Total & & & 13,962 & 277 & 19.8 \\
\hline
\end{tabular}

${ }^{1}$ Sex of the last two previous pregnancies.

Table 3. Neonatal mortality of female neonate according to reproductive history of mother

\begin{tabular}{|c|c|c|c|c|c|}
\hline \multirow[b]{2}{*}{ Cohort } & \multicolumn{2}{|c|}{ P.eproductive history of mother } & \multicolumn{3}{|c|}{ Neonatal mortality } \\
\hline & Parity & $\begin{array}{c}\text { Sex of previous } \\
\text { pregnancies }\end{array}$ & $\begin{array}{l}\text { Popula- } \\
\text { tion }\end{array}$ & Deaths & Rate \\
\hline$I$ & 1 & None & 5,375 & 74 & 13.8 \\
\hline$I I$ & 2 & Male & 1,952 & 35 & 17.9 \\
\hline III & 2 & Female & 1,799 & 21 & 11.7 \\
\hline$I V$ & $>2$ & Male and male ${ }^{1}$ & 1,088 & 24 & 22.1 \\
\hline$V$ & $>2$ & Male and female ${ }^{1}$ & 2,135 & 23 & 10.8 \\
\hline$V I$ & $>2$ & Female and female ${ }^{1}$ & 932 & 8 & 8.6 \\
\hline Total & & & 13,281 & 185 & 13.9 \\
\hline
\end{tabular}

${ }^{1}$ Sex of the last two previous pregnancies.

Table 4. Relative risk of dying of male neonate compared with female neonate during neonatal period, according to reproductive history of mother

\begin{tabular}{|c|c|c|c|}
\hline \multirow[b]{2}{*}{ Cohort } & \multicolumn{2}{|c|}{ Reproductive history of mother } & \multirow{2}{*}{$\begin{array}{l}\text { Relative risk: } \\
\text { male death rate/ } \\
\text { female death rate }\end{array}$} \\
\hline & Parity & Sex of previous pregnancies & \\
\hline$I$ & 1 & None & 1.44 \\
\hline$I I$ & 2 & Male & 1.07 \\
\hline III & 2 & Female & 1.91 \\
\hline$I V$ & $>2$ & Male and male & 0.49 \\
\hline$V$ & $>2$ & Male and female ${ }^{1}$ & 2.03 \\
\hline$V I$ & $>2$ & Female and female ${ }^{1}$ & 2.69 \\
\hline
\end{tabular}

${ }^{1}$ Sex of the last two previous pregnancies

when reproductive antecedents of the mother are taken in consideration. At parity 1 , early neonatal mortality of male neonates is higher than mortality of female neonates. However, at parity 2 , if the conceptus of the first pregnancy was male, the risk of dying is the same whatever the sex of the neonate. If the mother has had two successive male pregnancies before, female neonatal mortality is higher than male neonatal mortality. In all other types of sex-related maternal antecedents, the risk of dying is higher for male neonates. There is an ascending progression (Fig. 1) of relative risk of dying of male neonates compared with female neonates in relation with reproductive antecedents in the following order: (male, male) $\rightarrow$ (male) $\rightarrow$ (no previous pregnancy) $\rightarrow$ (female) $\rightarrow$ (female and male) $\rightarrow$ (female, female). This is the result of the conjugation of an ascending progression of male 


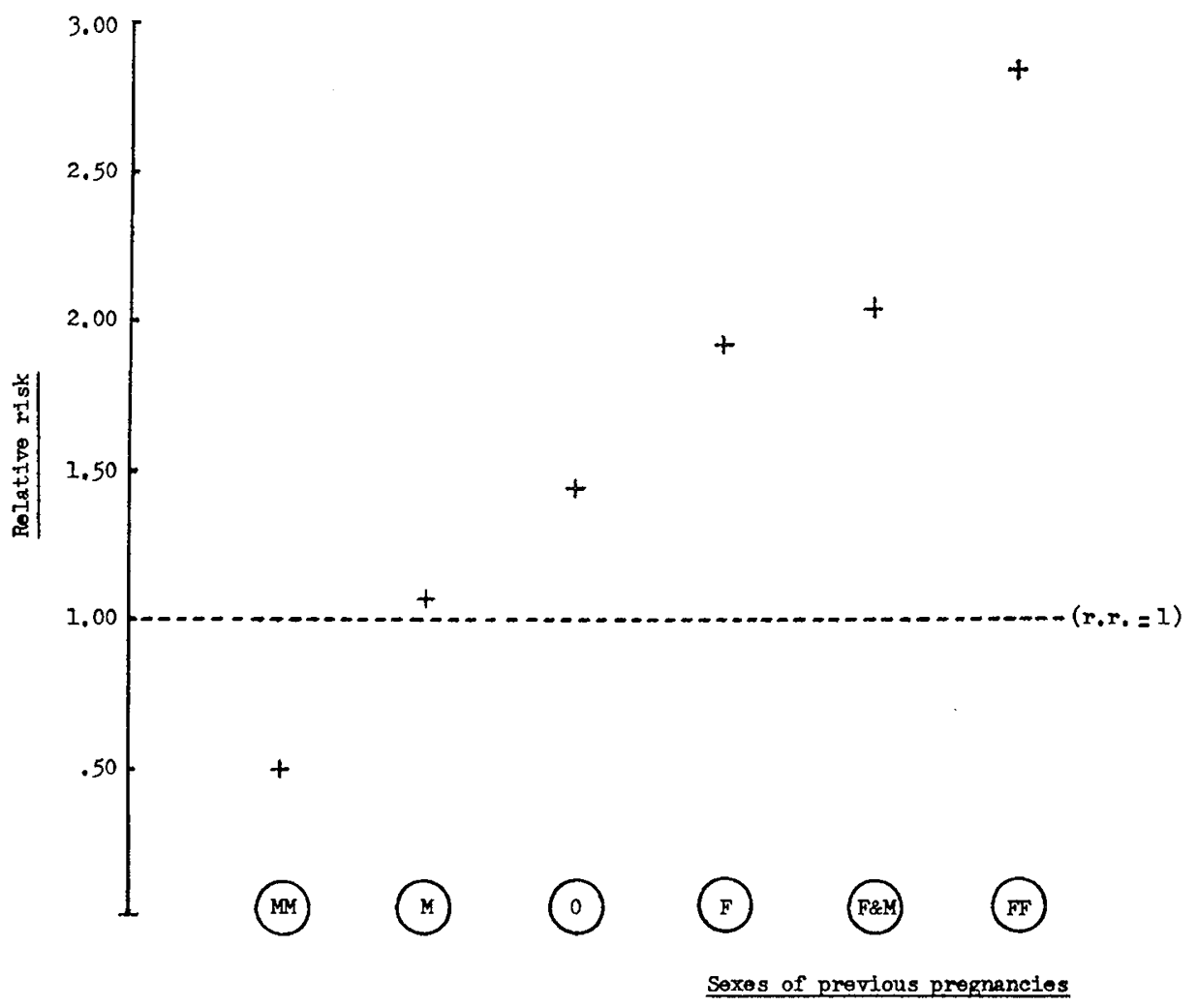

Fig. 1. Relative risk of dying during the first week of life of male neonate compared with female neonate, according to the sex-related reproductive history of the mother (the relative risk is the ratio of male death rate to female death rate). F: female, $M$ : male, $0:$ no previous pregnancy.

mortality, and a descending progression of female mortality according to the same order. A pattern seems to emerge from these results that survival of the neonate during the neonatal period is favored by previous maternal pregnancies of same sex and disfavored by previous pregnancies of opposite sex.

Neonatal mortality is influenced by endogenous as well as exogenous factors. If an association between neonatal mortality and sexes of previous pregnancies were confirmed, it would be essential to rule out, first, all possible exogenous explanations. In particular, environmental factors such as care, parental behavior, socioeconomic conditions, etc ..., susceptible to being correlated with neonatal survival, have to be analyzed in order to trace a possible association with maternal sex-related reproductive antecedents. Nevertheless, it is, at first sight, difficult to conceptualize such an environmental factor able to affect a newborn baby of a given sex, whose mother has had previously two pregnancies of the same sex as this baby, so that it has twice the chance of surviving of its opposite sex counterpart.

Early neonatal mortality and late fetal mortality partly depend upon the same factors. If there is an identical pattern of variation of fetal mortality with reproductive maternal history, the sex ratio at birth is supposed to be influenced. If the risk of dying of a fetus is lower after previous maternal pregnancies of the same sex as its own, there could be a positive correlation between the sexes of consecutive births. Several studies of sex-distribution in sibships concluded that such an association exists $(2,16,27,28)$. However, the correlation, although significant, is of slight amplitude and other studies have failed to demonstrate an association between sexes of consecutive births $(8,9,14,15)$. The sex ratio depends also upon the early fetal mortality and the primary sex ratio. The sex-differential mortality during the early period of gestation is not necessarily identical with the sex-differential mortality during the late period of gestation (19), and the sex ratio at conception which determines the size of populations both male and female at risk is still unknown (30).

The association found between the risk of dying of a neonate and the sex of previous pregnancies of its mother is compatible with an immunologic hypothesis of the sex-differential perinatal survival, such as formulated in the introduction. In addition it is possible from the present results to refine the formulation of this hypothesis. Sex-differential survival of conceptuses during the perinatal period would be due to sex-differential conceptomaternal immunologic interactions. An advantage in survival of the female fetus results from these interactions in primiparous mothers. However, immunologic behavior of the mother is altered by previous contact with fetal antigens. Consequently, sex-differential survival varies with sex-related antecedents of the gravida. Previous sensitization of the gravida by male conceptus provides an advantage in survival for a subsequent male conceptus, and previous sensitization by female pregnancy provides an advantage in survival for a subsequent female conceptus. Repeated contacts with antigens in successive pregnancies, of the same sex, increase the sensitization of the gravida and in the same way affect the survival of the neonates.

\section{SUMMARY}

The risk of dying of a neonate during the first days of its life is thought to be higher for males than for females. The present study suggests that this phenomenon is not constant when sex-related reproductive antecedents of the mother are taken into consideration. The analysis of the sex-differential early neonatal mortality experienced by a population of 27,343 neonate has revealed an association between the risk of dying of a neonate and the sex of previous pregnancies of its mother. The survival of the neonate during the neonatal period seems to be favored by previous maternal pregnancies of same sex as its own, and disfavored by the other pregnancies. An 
immunologic hypothesis for the sex-differential of perinatal survival has been formulated from these results.

\section{REFERENCES AND NOTES}

1. Baird, D., Walker, J., and Thomson, A. M.: The causes and prevention of stillbirths and first week deaths. J. Obstet. Gynaec. Brit. Emp., 61: 433 (1954).

2. Berstein, M. E.: Techniques of stratified sampling in the study of variation of the human sex ratio. Eugen. Quart., 14: 54 (1967).

3. Breyere, E. J., and Barrett, M. K.: "Tolerance" in postpartum female mice induced by strain specific matings. J. Nat. Cancer Inst., 24: 699 (1960).

4. Brown, E. S.: Foetal erythrocytes in the maternal circulation. Brit. Med. J., 1: 1000 (1963).

5. Burstein, R. H., and Blumenthal, H. T.: Immune reactions of normal pregnancy. Amer. J. Obstet. Gynecol. 104: 671 (1969).

5. Clarke, B. C., and Kirby, D. R. S.: Maintenance of histocompatibility polymorphisms. Nature, 211: 999 (1966).

7. Dewey, W. J., Mann, J. D., Wilson, D. A., and Jackson, C. E.: Apparent interaction between $\mathrm{Xg}^{\mathrm{a}}$ blood group system and the sex ratio. Nature, 206: $412(1965)$

8. Edwards, A. W. F., and Fraccaro, M.: The sex distribution in the offspring of 5,477 Swedish ministers of religion, 1585-1920. Hereditas, 44: 447 (1958).

9. Edwards, A. W. F., and Fraccaro, M.: Distribution and sequence of sexes in a selected sample of Swedish families. Ann. Hum. Genet., 24: 245 (1960).

10. Eichwald, E. J., and Silmser, C. R.: Skin. Transplant. Bull., 2: 148 (1955).

11. Fraser, I. D., and Raper, A. B.: Observation of compatible and incompatible foetal red cells in the maternal circulation. Brit. Med. J., 2: 303 (1962).

12. Freda, V. J.: The Rh problem in obstetrics and a new concept of its management using amniocentesis and spectrophotometric scanning of amniotic fluid. Amer. J. Obstet. Gynec., 92: 341 (1965).

13. Goodman, H. S., and Masaitis, L.: Analysis of the isoimmune response to leukocytes. I. Maternal cytotoxic response to fetal lymphocytes. Proc. Soc. Exp. Biol. Med., 126: 599 (1967).

14. Greenberg, R. A., and White, C.: The sequence of sexes in human families. Biometrics, 20: 384 (1964).

15. Greenberg, R. A., and White, C.: The sexes of consecutive sibs in human sibships. Hum. Biol., 39: 374 (1967).

16. Harris, J. A., and Gunstad, B.: The correlation between the sex of human siblings. Genetics, 15: 445 (1930).

17. Herzenberg, L. A., and Gonzales, B.: Appearance of H-2 agglutinins in outcrossed female mice. Proc. Natl. Acad. Sci. U.S.A., 48: 570 (1962).

18. Kaliss, M., and Dagg, M. K.: Immune response engendered in mice by multiparity. Transplantation, 2: 415 (1964).

19. Keller, C. A.: Embryonal sex ratios in animals and man. Thesis, University of California, Berkeley (1969).

Copyright $\odot 1975$ International Pediatric Research Foundation, Inc.
20. Kirby, D. R. S., McWhirter, K. G., Teitelbaum, M. S., and Darlington, C. D.: A possible immunological influence on sex ratio. Lancet, ii: 139 (1967).

21. Klemperer, M. R., Osthold, M., Vasquez, D., Diamond, L. K.: The incidence of complete complement-fixing platelet antibodies in pregnant women. Vox Sang., 11: 124 (1966).

22. Lanman, J. T., and Herod, L.: Homograft immunity in pregnancy. The placental transfer of cytotoxic antibody in rabbits. J. Exp. Med., 122: 579 (1965).

23. MacMahon, B., and Pugh, T. F.: Epidemiology: Principles and Methods (Little, Brown and Co., Boston, 1970).

24. Maroni, E. S., and Parrott, D. M. V.: Progressive increase in cell mediated immunity against paternal transplantation antigens in parous mice after multiple pregnancies. Clin. Exp. Immunol., 13: 253 (1973).

25. Payne, R.: The development and persistence of leukoagglutins in parous women. Blood, 19: 411 (1962).

26. Plato, C. C., Mann, J. D., Schwartz, J. T., and Leyshon, W.: The role of $\mathrm{Xg}^{\mathrm{a}}$ blood group incompatibility in fetal loss. Acta Genet. Med. Gemell., 19:235 (1970)

27. Renkonen, K. O.: Is the sex ratio between boys and girls correlated to the sex of the precedent children? Ann. Med. Exp. Biol. Fenn., 34: 447 (1956).

28. Schutzenberger, M. P.: Résultats d'une enquête sur la distribution du sexe dans les familles nombreuses. Sem. Hôp. Paris, 25: 2579 (1949).

29. Soren, L.: Immunological reactivity of lymphocytes in multiparous females after strain specific matings. Nature, 213: (1967).

30. Stern, C.: Principles of Human Genetics, Ed. 3 (W. H. Freeman, San Francisco, 1973)

31. Tuffrey, M., Bishun, N. P., and Barnes, R. D.: Porosity of the mouse placenta to maternal cells. Nature, 221: 1029 (1969).

32. Vernier, M. C.: Sex-differential placentation: Immunological interactions between male conceptus and gravida during normal pregancy. Biol. Neonate (in press).

33. Warburton, D., and Naylor, A. F.: The effect of parity on placental weight and birth weight: An immunological phenomenon? A report of the collaborative study of cerebral palsy. Amer. J. Hum. Genet., 23: 41 (1971).

34. Zipursky, A., Hull, A., White, F. D., and Israels, L. G.: Foetal erythrocytes in the maternal circulation. Lancet, $i: 451$ (1959).

35. This study was supported in part by the Epidemiology Training Grant, $2 \Upsilon 01 \mathrm{GM} 00008$, from the National Institute of General Medical Sciences and by the General Research Support Grant, 5 S01 RR 05441 (10), from the National Institutes of Health, United States Public Health Service. The data used in this study were provided by the Child Health and Development Center (Kaiser Foundation Research Institute) supported by Public Health Service Grant, HD 00718, National Institutes of Health. 36. Requests for reprints should be addressed to: M. C. Vernier, M.D., Department of Health Care and Epidemiology, Faculty of Medicine, University of British Columbia, Vancouver 8, British Columbia, Canada.

37. Accepted for publication December 9, 1974. 